\title{
Commentary: The Gold Coast Health and Knowledge Precinct - a special type of Games legacy?
}

\section{Ned Pankhurst}

n.pankhurst@griffith.edu.au

A key concern for all cities and governments hosting major, facility-intensive sporting events is, 'What happens after the party?' This question has both a practical and a societal context, and it spawns the inevitable additional inquiries: Will we get a return on our investment? Will the infrastructure have ongoing use? Will the changes that the investment brings to the city be the ones we intended? Will people thank us for committing the city and the state to the adventure after the exhilaration of contest has subsided and the metaphorical dust has settled? Some of the answers are easy to determine: ongoing use of sporting facilities is a clearly defined metric, as are visitor intensity and revenue generation associated with those events. Similarly, transport infrastructure use and value can be readily assessed in terms of revenues, passenger movements and levels of public participation, and such judgements of success based on hard numbers can readily be drawn. Longer-term effects, such as perceptions of improvements in liveability and urban utility, social wellbeing and cohesion, are softer edged and take longer to emerge, but seem to fold themselves into city narratives in the wake of well-run and successful events, in a largely positive way. But what would happen if one of the planned legacy outcomes was to attempt to fundamentally change the face of the business and industry profile of the city? This is exactly the grand thinking behind the legacy opportunity of the Gold Coast Health and Knowledge Precinct (GCHKP).

The 2018 Commonwealth Games (GC18) provided this opportunity initially through the pragmatic need to find a suitably central state-owned location for the Athletes' Village with the search for a solution precipitating a decision on what to do with the area called Parklands. Parklands was a harness-racing, showgrounds and events site that was much loved but little used by Gold Coasters. It occupied a key potential site in an inoffensive but relatively unproductive way, and was protected from decisions over alternative use by its bizarrely iconic status in a young, developing city. The demands of CG18 broke that nexus and cleared the way - literally - for the development of the athletes' accommodation (which would remain after the Games) and associated temporary support facilities (which would not). 
This critical component of the GCHKP presented a post-Games development opportunity through the provision of a greenfield site in the form of a $29 \mathrm{Ha}$ Priority Development Area (PDA) overseen by Economic Development Queensland (EDQ) on behalf of the Queensland Government, and with planning and development input from a Steering Group representing major neighbours and stakeholders (City of Gold Coast, Gold Coast Health and Hospital Service and Griffith University). It would be a site linked to both north and south by light rail following the state government's commitment to build Stage 2 of the Gold Coast light rail line. So far so good. There now existed the land opportunity, there was focused government attention through the PDA-enabled master planning processes and the precinct partners demonstrated commitment by establishing and jointly funding a project office with a dedicated director and support staff. But this is still a long way from establishing an innovation precinct with the capacity to drive innovation and industry development for the city. The question was how to get from here to there.

It is probably worth starting with a consideration of the basic value proposition. Every two-pub town in Australia has an innovation zone, and if it is bigger than a football field it gets the grand appellation of 'precinct'. What was special about this one? Well, the neighbours for a start. A combination of GC18 and non-Games investment have brought eye-watering sums of money into the broader precinct over a relatively short period, and through that created a very substantial launch pad for innovation-focused investment. A broad stocktake shows $\$ 1.8$ billion invested in the Gold Coast University Hospital, \$300 million in the Gold Coast Private Hospital, \$500 million in recent Griffith University Gold Coast campus infrastructure, $\$ 2.1$ billion in both stages of the light rail project, $\$ 550$ million in the accommodation component of the GCHKP and \$150 million in precinct highway and transport upgrades. This investment forms the base for current employment of nearly 10,000 people across the two hospitals and Griffith University. Most importantly, the nature of that employment creates a critical mass of clinical, research and innovation expertise that quickly defines the GCHKP as more than your average innovation precinct and makes the innovation aspirations both possible and plausible.

There is another thing that Gold Coast Mayor Tom Tate calls the 'San Diego effect'. It is the combination of high-quality research institutions and healthcare provision mixed with government investment, innovative city thinking, affordable housing, good schools and a decent beach. It is present in some equivalent form in all innovation-focused cities around the world, where individuals and corporate entities choose to invest, and where young talented and mobile workforces choose to settle and live. A critical part of that decision is lifestyle, and the soil has to be good for growing children. However, even with the requisite components in place, innovation and investment therein is not a spontaneous event; its growth requires focus, planning and the catalytic spark of some keystone investment.

First, what or who did we want in the precinct? Queensland, and particularly South-East Queensland, is awash with development opportunities, and property development is the bread of the Gold Coast economy (tourism is the butter). There was always a risk that the GCHKP would be seen as yet another one of these development opportunities, and could become the target of rank and file commercial development - all good and worthwhile but also more appropriately available at other locations in the city. The opportunity here was special, and it was clear 
from the outset that there would need to be some access rules in place that recognised and supported that novelty. The precinct Steering Group under the watchful gaze of EDQ developed a list of occupancy criteria that development bids would need to address. Projects would need to be innovation focused; they would need to bring additional new employment to the precinct - not simply move it round within the city. They would need to demonstrate leverage off the academic, research and clinical expertise in the precinct, have a clear link to a global industry sector with visible international connections and capacity, and, as a consequence, be able to target export markets. And this was not to be a government-financed development program: proponents need to come with an infrastructure investment plan for capital development. EDQ retains the final say on land access supported by design and use expectations articulated through a precinct master plan.

Will the criteria work in delivering an integrated world's best practice innovation precinct? It is too early to tell, but what has emerged is striking commonality in the vision for the precinct among steering group members, despite the different operational priorities and strategic aspirations that the different entities bring to the table. This has to be about new industries and opportunities; it has to be about building innovation that provides the springboard for new industry growth for the city; it has to build off existing strengths; and it has to be about broadening the training and employment opportunities for young graduates in the city. But the first steps are always the hardest. How do we get from a position of 'We don't know what this is going to look like yet but it's going to be great' to being able to articulate what will happen, how it will work and what will in turn grow from the investment by first movers? At the time of writing, there are three foundation proposals at various stages of development, one developer led, one business led and a university initiative that was conceived as a lighthouse project based on the 'what-comes-nextwill-depend-a-lot-on-what-we-build-first' principle.

Enter a timely intersection with a different conversation. For some time, Griffith University has been investing in a range of research institutes and technologies designed to support the transition of basic research and knowledge into tangible products and outcomes. A visible expression of this is the Queensland Micro and Technology Centre at our Nathan campus, where we have a semiconductor factory that builds the only global supply of silicon carbide-on-silicon wafers at a size and reproducibility that allows commercial-scale testing of the platform for a range of products and solutions in the electronics industry. Investigations have included using the wafers as the base for development of a new and more efficient way to build common electronic devices. This advance started us thinking about the broader context of advanced manufacturing and the opportunity to bring this to fruition around a range of Gold Coast campus-based technologies, essentially using the same operational blueprint. The concept of the Advanced Manufacturing (AdAM) Institute was born.

About the same time that we at Griffith were considering the fact that everybody was touting 'advanced manufacturing' as the saviour of the Australian manufacturing sector - although why would you do manufacturing that was 'not advanced'? - we had some blunt but aligned input from several different directions at the same time - from our researchers, our industry partners, our commercialisation specialists and advisers - that we were missing the point. Australia, it seems, suffers particularly severely from a global problem in the relationship between research and 
industry. There is no question that the world's universities are formidable furnaces of knowledge creation and that a substantial part of the knowledge finds its way into products and services that mostly make the world a better place. There is also no question that this is done better in some places than others, and where it works well it is usually on the back of established, mature, innovative industries together with researchers who are attuned to the way industry needs to work. Both of these conditions are harder to satisfy in situations where the intention is to build new industries. This applies to most innovation precincts.

Researchers are very good at thinking up new ways of seeing the world, developing these intellectual constructs into new stuff at the lab bench and articulating at some level a proof-of-concept that describes what you might be able to do with the discovery. Historically, research then cups its hands around the precious item and carries it reverently to industry so that they can test it, sort out what it is good for, retool their factories and then attempt to break into a new market with an untested product while along the way sharing the benefits of the discovery with the inventor. Not surprisingly, this is not overwhelmingly attractive to industry; industry takes all of the risk around product development and has to do that on faith rather than the knowledge that the product will work, will be scalable and will be profitable. Why not, we asked, take a different approach that shares more of the risk of product development with industry and delivers discovery to them in a more digestible form and at a more advanced stage of the discovery-toproduct pipeline? This shifts the focus from manufacturing to prototyping and testing. Consequently, before it was even born, AdAM was dead and ADaPT (the Advanced Design and Prototyping Technologies Centre) was conceived.

If we were to proceed with ADaPT, where should it rest? In theory, we should target existing industry clusters and critical mass, and build it on the back of things we already did well. Universities have the useful privilege of trying things outside of the scope of fiscal constraints, so we decided that one out of three of the desirable conditions would do. We would build on the back of things that we already did well but we would position ourselves as the magnet for new and developing industries in a space where everything we did would make a difference and where there was currently no significant industry base. It was decided: $\mathrm{ADaPT}$ would be proposed as a lighthouse development project for the GCHKP.

So the Griffith team did a revised stocktake of precinct research capacity around the concept of ADaPT rather than AdAM and Di Dixon, the GCHKP Project Director, conducted a wide-ranging industry engagement process ('If we were to do this, what would you need or what would be of interest to you?'). The research stocktake developed increasing comfort with the approach, not in terms of changing our view of what we were good at but by increasing the accessibility of industry conversations for researchers. Many who could not see over the horizon to a commercially viable product were much more comfortable with the shorter journey to a prototype and consequent cycles of testing and refinement. We were shifting the point of engagement but still mostly talking about having researchers do what they were good at and comfortable with, and similarly for industry. This was a much more sensible effort to meet in the middle of our respective experience spans. What existing industry wanted mostly aligned with our understanding, with only a few surprises. There was strong interest in the potential of additive manufacturing (3D printing), a desire to understand what new materials were or would be available, 
and how these went together with new manufacturing processes to allow solutions to problems for which they currently sometimes didn't have answers. The not-so-shocking surprise was how this nearly always came back to a discussion around design, and that either explicitly or implicitly this was a fundamental requirement for a whole range of industries, and it needed to be central to our thinking. It was, but if we needed any further encouragement to keep it front and centre, we now had it.

Over iterative cycles of consultation and planning, the engine of ADaPT began to take shape. ADaPT would be an industry-focused facility for rapid prototype development, allowing the design, fabrication and testing of products based on intelligent design models. To achieve this, it would need to host materials scientists, product designers and specialists for 3D scanning and visualisation, advanced fabrication experts including 3D printing, functional computer modelling, and staff and facilities for the testing of materials and prototypes. Establishment research programs and products would include personalised medical implants and the utilisation of 3D modelling and printing for surgical training; cardio and neuromuscular treatment devices, microfluidic and 'soft' 3D conductive systems, functional biomaterials and, as a central core, 3D functional modelling and the use of intelligent digital twins. A digital twin is a computer-generated representation of an object that allows you to model the effect of design and materials changes, and predict the outcomes of those changes, before you actually fabricate the next iteration of a prototype or product. It is a very powerful tool for taking the guesswork out of the design and manufacturing process so you have a very clear understanding of what a prototype will look like, and how it will perform in advance of when you actually fabricate it.

For me, the excitement comes not just from the technologies themselves but from the types of problems that can be attacked. In the medical space, these include personalised orthopaedic implants and the specialised surgical tools needed to conduct that personalised surgery, wearable rehabilitation devices for treating and managing neuro-musculoskeletal conditions, implants composed of bio-scaffolds that provide the framework for tissue repair by the patient's own cells, and components for artificial hearts. Materials science research pursues the development of cheap catalysts to convert waste biomass (e.g. from the sugar cane industry) into useful materials, improvements to solar cell technology, smart systems for energy conservation in buildings, prototype electrodes for long-life rechargeable batteries, nanoparticle-based sensor systems and the development of advanced optical systems. Biomaterials products range across vaccine delivery systems, natural fibre reinforced plastics, diagnostic products and bioplastic materials with embedded anti-microbial activity. This is not an exhaustive list, and it rapidly became clear that developing a product pipeline would not be our problem; rather, our challenge would be prioritising around the mix of good science, exciting opportunities and industry willingness to engage at a scale and across timeframes most likely to produce tangible results quickly.

Through this period, the internal Griffith University planning approvals were delivered, a project sum of $\$ 80$ million was proposed and approved as part of the University Capital Management Plan, and we began the serious business of deciding what was in and what was out in the context of making our money stretch as far as possible while not skimping on build quality, or the quality and capacity of the 
research platforms contained in the facility. There were external requirements at play too. The precinct master plan delivered expectations in relation to building form and quality, and the site for ADaPT made this particularly important. We reasoned that if this was to be a 'lighthouse' project, it needed to be where it was easy to see, and it also needed to be somewhere that made it clear that this facility was both part of the Griffith estate, and also a conduit into the industry facilities that someday will surround it. That meant that there was only one site for ADaPT on the Parklands Drive frontage adjacent to other campus buildings on the other side of the street, and happily this was a proposition that was acceptable to EDQ. It did, however, mean that in addition to being functional, the building had to make a statement as an entry portal to the precinct and the design would need to reflect this. So the simple task presented to the architects selected by the university for the project (a partnership between the firms Conrad Gargett and Blight Rayner) was to build us something big, make it grand, make the design breathtaking, accommodate all the special facilities that we would need without compromising that design and, by the way, there is no chance that this project can go over budget. Design work is now well advanced, and our architects show every chance of delivering on the requirements.

So there is now a purpose and view on how to get there, a clear understanding of the facility and infrastructure requirements, a site, a design, a budget and a construction plan. ADaPT will rapidly take shape in a material sense. But will we have an outcome that really is place and function defining in the way that we hope? Rattling round in my mind was a comment that I had heard made by an industry member of an esteemed group assembled in Sydney as part of a series of AustraliaAmerica dialogue forums. The view espoused from Sydney was that, despite the fashion, there was not enough room in Australia for many effective innovation precincts - only two in fact: the one where the meeting was at Macquarie Park and, if there had to be another one, then perhaps the critical mass of biomedical research that defined Parkville in Melbourne. All the rest, went the argument, were a waste of time, energy and money. Once my indignation had settled, I thought about the wisdom of this position, which I suspect reflects a broader view from Sydney and Melbourne that innovation belongs in big places with big investment profiles, and Australia has two of these so that's it really - the rest is play. The interesting thing about innovation, though, is that it doesn't ask permission to occur, it is not constrained by what has gone before (otherwise by definition it would not represent innovation) and it is refreshingly localised in context. Big, audacious global solutions repeatedly come from people trying to solve a problem next door. And there is also a moral principal here. Innovation changes people's lives; it should not solely be the preserve of those who got there first or who already hold the ground. I had no concerns that what we were trying to do on the Gold Coast wasn't ethically, morally and pragmatically the right thing to do; however, this didn't stop the question of whether our particular approach was the right one.

With this in mind, Dr Jens Tampe, Deputy Director of Griffith Enterprise (Griffith's commercialisation arm) undertook an assessment of points of commonality and difference between what we were proposing and activities under development or in place in other locations, and interestingly the view developed that there were gaps in the models represented by both of the two self-identified precincts mentioned earlier. In addition to there being intensive international investment in 
the area, Australia has a number of well-positioned initiatives in place. A nonexhaustive scan identifies the federal government's Advanced Manufacturing Growth Centre in Geelong, the Innovative Manufacturing Co-operative Research Centre based in Carlton, Victoria, CSIRO's Lab22 directed at additive manufacturing using metals and advanced metal alloys, the RMIT Advanced Manufacturing Precinct targeting aerospace automotive and bio-engineering, QUT's Heston BioFabrication Institute directed at bio-fabrication and personalised medicine and Flinders University's Tonsley Innovation Precinct in Adelaide, addressing priorities in medical devices, renewable energy, software development and mining services. All are well-resourced, expertise-based, quality programs directed at making sure Australia finds and maintains its place in a global innovation economy. Where was the space for our project?

A consistent emerging theme was that our focus on functional digital design, supported by the research and fabrication capacity rather than the technology itself, was a defining point of difference. Digital twinning and cycles of prototype optimisation require the clients to be immersed in the design process from the outset - our 'partners in design' approach coupled with in-house materials development and molecular-level characterisation offer a very specific and attractive value proposition. We had always had a view that the design core of ADaPT was critical to success, but we had something of an epiphany when we were grappling with another design requirement imposed by the PDA master planning process. All the GCHKP developments have a requirement to contribute to street-level activation of the precinct. Initially this was conceived as predominantly retail-focused activity on the ground plane of most buildings to build the level of human traffic and engagement. We had the mandatory cafe in mind until we realised that we were probably missing a trick. Other providers in the precinct will do a good job of supporting retail needs but our point of contact was the design core. Placing it on the ground floor as the main point of engagement would create both the desired human flow and the point of connection between external users and the potentially impermeable face of a high-end research and development facility.

This realisation triggered a second 'Why didn't we think of it before?' conversation. Griffith is host to a Centre for Design Innovation and Research (CDAIR), which was initially developed from our South Bank design program but has been relocated to our Gold Coast campus under the leadership of new foundation director Professor Ming Cheung. CDAIR is the first of its kind in Australia, with an overarching vision to foster economic, socio-cultural and technological growth, and to promote human wellbeing through design innovations. We realised that the things that bring clients to CDAIR are the same needs and motivations that we had identified through the technology focus of the ADaPT concept. CDAIR has the objective of positioning itself as 'an interdisciplinary centre for research and consultancy in experience design in relation to services, products, systems, media, health and learning, and as a hub of innovation linking design with other fields such as medicine, technology, engineering, education, architecture and business'. As often happens in large institutions like Griffith, we had been running parallel activities addressing the same outcomes. CDAIR formally became part of the $\mathrm{ADaPT}$ program and will occupy key engagement space on the entry level of the building. 
Despite our conviction that we were on the right track, an elephant in the room was the inescapable fact that high-end additive manufacturing requires experience and capacity with 3D metal printing. We didn't have that — in fact, at that time no one in Queensland did. We had a well-established program of design and 3D printing using polymers ('plastic' printing), but it was clear to us that there was a steep learning curve for entry into printing with metals and metal alloys. Some years earlier, I had been on a 'field trip' to Australian fabrication facilities with Professor Huijun Zhou, our leader in applications of smart materials for energy and environmental solutions. The intention was for me, under Huijun's guidance, to get a better understanding of the advanced fabrication facilities in Australian research institutions, and how well they were positioned (or not) to respond to, and engage with, industry needs. On our inspection list was the impressive metal printing facility at the Clayton campus of Monash University, where the team had just completed the not so trivial process of 3D-printing a jet engine (a Safran gas turbine from a Falcon executive jet for those interested). Since then, they have acquired one of the largest metal printers in the world and positioned Australia as a serious player in the prototype additive manufacture of industrial-scale metal objects. We didn't have quite the same need for scale, but we did need to be able to apply the same principles of precision and sophistication to our work. It was helpful to understand what we were up for, and the visit started a process that culminated in us understanding that for ADaPT to work properly, we probably needed to build a small metal printing facility first.

So what came to be known as 'ADaPT 1.0' was conceived, gestated and born in the form of a medium-scale metal and advanced polymer 3D printing design and printing facility that we placed alongside an existing 3D printing and design suite on our Gold Coast campus. We revamped some existing space to meet the space needs of the gear and invested in a high-end Renishaw AM400 metal printer with capacity for printing in titanium, cobalt chromium, stainless steel and aluminium. It currently remains the only metal-capable printer in Queensland. This was complemented by a FORMIGA P110 polyamide printer that allowed us to move to very high precision plastic printing both for products in their own right, but also as a test bed for the production of the more expensive metal equivalents. We were gratified when the installation specialists from Renishaw told us that this was the best designed purpose-built facility that they had done an installation into. But then it was supposed to be. If this was a dry run for big brother ADaPT, then it had to be as right as we could make it, otherwise we wouldn't learn anything from the process and, more importantly, we wouldn't be building our skill base in the way that we needed to. It also mimicked the structural intent of the larger facility that would follow, with entry engagement space for interaction with clients and researchers, digital design space and finally 'back of house', but nicely behind glass so we could showcase the printers. ADaPT in miniature. We recruited new staff to commission the equipment and begin the process of developing capacity among our research staff and graduate students, with the view that we could manage a careful 'ramp up' in activity to coincide with the opening of a larger version in the ADaPT building.

Except it didn't quite work that way. Without advertising that we were open for business, and in advance of us deciding what the business model for operating the new facility would be, people with problems and ideas started appearing at the door. The attraction is that additive manufacturing technology enables the 
production of highly complex geometries that are often difficult or impossible to achieve using traditional manufacturing techniques. Design becomes much less constrained by how the product needs to be made. The range of interest was both predictable and surprising, and included medical devices, aerospace technologies, general manufacturing and 3D-printing of anatomical models for surgical planning and training. Almost before we were ready, we had to think about modes of engagement, priority for printer access and pricing - all operational details that we had thought could be dealt with later but will now be taken into ADaPT as items of experience. We suspect that this is an early warning of how $\mathrm{ADaPT}$ and the precinct will operate; there is significant existing demand for design and fabrication services even without the development of new industry players. Each level of development creates additional momentum. A nice example of this was the recent decision of a major global software company that specialises in 3D modelling to shift its Australian headquarters from Sydney to Griffith Gold Coast and ultimately to $\mathrm{ADaPT}$, on the back of the university's ADaPT 1.0 investment.

Bringing this back into the broader discussion of how the GCHKP will work, we are now more firmly convinced than ever that the initial projects for precincts like this are incredibly important. The first-movers help define the space, have a major role in determining who the subsequent neighbours will be and act as investment attractors. Investment follows investment. We are confident that ADaPT will do all of these things. The potential of the fully populated precinct is impressive. There is scope for 174,000 square metres of floor space over fifteen development sites (for comparison, $\mathrm{ADaPT}$ will use about 10,000 square metres of this), and the creation of 12,500 new jobs across a wide range of industries and services, with precinct employment totaling over 26,000, or 11 per cent of the current Gold Coast workforce. Third-party modelling suggests that even without the effect of flowon development elsewhere in the city, this will generate gross value of $\$ 2.9$ billion annually for Queensland's economy. None of this is accidental. It follows from the planning decisions of government, the investment profile supporting the GC18, the willingness of the precinct partners to engage in city building, our collective vision of what can and should occur here, and Griffith University's determination to invest. It also raises a more general thought about legacy: legacy realization is not a passive exercise; without assertive and continued investment, strategic engagement and partnership, none of the legacy benefits are a given. The direct investment in GC18 has created a once-in-a-generation opportunity. The rest is up to us. 